\title{
PDS
}

\section{All-cause pneumonia in children after the introduction of pneumococcal vaccines in the United Kingdom: a population-based study}

\begin{tabular}{|c|c|}
\hline Journal: & Pharmacoepidemiology and Drug Safety \\
\hline Manuscript ID & PDS-18-0370.R1 \\
\hline Wiley - Manuscript type: & Original Report \\
\hline $\begin{array}{r}\text { Date Submitted by the } \\
\text { Author: }\end{array}$ & $\mathrm{n} / \mathrm{a}$ \\
\hline Complete List of Authors: & $\begin{array}{l}\text { Lau, Wallis; University College London School of Pharmacy, Centre for } \\
\text { Paediatric Pharmacy Research, Research Department of Practice and } \\
\text { Policy; The University of Hong Kong, Centre for Safe Medication Practice } \\
\text { and Research, Department of Pharmacology and Pharmacy, Li Ka Shing } \\
\text { Faculty of Medicine } \\
\text { Bielicki, Julia; Institute for Infection and Immunity, Paediatric Infectious } \\
\text { Disease Research Group, St. George's University of London } \\
\text { Tersigni, Chiara ; Institute for Infection and Immunity, Paediatric } \\
\text { Infectious Disease Research Group, St. George's University of London } \\
\text { Saxena, Sonia; School of Public Health Imperial College London and } \\
\text { Chartfield Surgery, Primary Care and Public Health } \\
\text { Wong, Ian ; The University of Hong Kong, Centre for Safe Medication } \\
\text { Practice and Research, Department of Pharmacology and Pharmacy, Li } \\
\text { Ka Shing Faculty of Medicine; University College London School of } \\
\text { Pharmacy, Centre for Paediatric Pharmacy Research, Research } \\
\text { Department of Practice and Policy } \\
\text { Sharland, Mike; Institute for Infection and Immunity, Paediatric } \\
\text { Infectious Disease Research Group, St. George's University of London } \\
\text { Hsia, Yingfen; Institute for Infection \& Immunity, Paediatric Infectious } \\
\text { Disease Research Group, St. George's University of London }\end{array}$ \\
\hline Keywords: & pneumococcal conjugate vaccine, pneumonia, children, primary care \\
\hline Abstract: & $\begin{array}{l}\text { Purpose: To explore the impact of PCVs in preventing childhood } \\
\text { pneumonia in the United Kingdom. } \\
\text { Methods: We carried out a population-based study to assess the trend of } \\
\text { all-cause pneumonia in children aged <10 years between } 2002 \text { and } \\
2012 \text {. Data were obtained from the IMS Disease Analyzer, a primary } \\
\text { care database in UK. Three time-periods were defined to estimate } \\
\text { monthly incidence: pre-PCV7 (January } 2002-\text { August 2006), post-PCV7 } \\
\text { (September 2006-March 2010), and post-PCV13 (April 2010-December } \\
2012) \text {. Interrupted time series analysis (ITS) was performed to assess } \\
\text { any immediate change or gradual change in the monthly incidence of } \\
\text { pneumonia between pre- and post-vaccination introduction. } \\
\text { Results: A total of } 4,228 \text { children with at least one all-cause pneumonia }\end{array}$ \\
\hline
\end{tabular}


episode were identified. The overall annual incidence rate of all-cause pneumonia declined by $37 \%$ from 3.8 episodes $/ 1,000$ person-years in 2002 to 2.4 episodes/1,000 person-years in 2012. Results of ITS analyses indicated that the incidence did not decline immediately after the introduction of PCV7 and PCV13. The incidence declined gradually in children aged $<2$ years (IRR $=0.98 ; 95 \% C I=0.97-0.99$ ) post-PCV7, and levelled off during post-PCV13 (IRR $=1.00 ; 95 \% \mathrm{CI}=0.99-1.02)$. No significant changes in incidence trend was observed in children aged 2-4 years $(I R R=0.86 ; 95 \% C I=0.68-1.07)$ and $5-9$ years $(I R R=0.92$; $95 \% \mathrm{CI}=0.73-1.15)$ after PCV13 introduction.

Conclusions: In the UK, the incidence of all-cause pneumonia in children $<2$ years declined after the introduction of PCV7 and levelled off in the first two years of introduction of PCV13. Continual monitoring is warranted to assess the population impact of PCV13 in preventing childhood pneumonia in the long-term.

\section{SCHOLARONE ${ }^{\text {m }}$ Manuscripts}




\section{CONFLICT OF INTEREST DISCLOSURE}

The Editors of Pharmacoepidemiology and Drug Safety recognize that most studies in pharmacoepidemiology cost money and thus pose a potential conflict of interest. As a conflict of interest may affect the assessment or judgment of an author, we ask that all authors (not just the Corresponding Author) complete the following form.

For Co-authors: Please complete questions 4-10. Completed forms should be saved, and emailed as an attachment to the Corresponding Author.

For Corresponding Authors: Please complete all questions. It is the responsibility of the Corresponding Author to submit completed forms on behalf of all co-authors via Manuscript Central at the point of manuscript submission.

\section{Corresponding author only (Co-authors go to Question 4):} POTENTIAL STUDY INTERPRETATION CONFLICTS

1. Some or all of the data that were used in this study were provided by a company with a vested interest in the product being studied.

No

2. The sponsor of this project had the right of commenting but the authors retained the right to accept or reject comments or suggestions.

No

3. The sponsor of this project had the right of final editing and/or approval of the manuscript submitted.

\section{Corresponding author and Co-authors:}

POTENTIAL FINANCIAL CONFLICTS

4. I, my spouse, or one of my dependent children is an employee of a company whose product is being studied.

No

5. I, my spouse, or one of my dependent children has significant equity interest (>USD 10,000) in the company that owns the product being studied.

No

6. In the past three years I have:

- been paid as a consultant (or in a similar capacity) by a company with a vested interest in the product being studied, on issues related to the product being studied;

No 
- been paid as a consultant (or in a similar capacity by a company with a vested interest in the product being studies, on issues unrelated to the product being studied; No

- received research or educational support from a company with a vested interest in the product(s) being studied.

7. A company whose product is being studied has provided funding to support the work on this project. Yes

If you have answered YES to any of the above questions, or if you have additional personal, commercial or academic conflicts of interest, please draft a statement to publish with the article. e.g., $A B$ has been reimbursed by Safe Drug Ltd. for international conference attendance.

This study is funded by a Pfizer unrestricted educational grant

8. Manuscript title (first six words are sufficient)

All-cause pneumonia in children after the introduction of pneumococcal vaccines in the United Kingdom: a population-based study

9. Author's full name (a separate form must be submitted for each author)

\section{Dr Yingfen Hsia}

10. In checking this box, I confirm I have completed this form to the best of my knowledge. $\square$

This form is available online by clicking here 


\section{CONFLICT OF INTEREST DISCLOSURE}

The Editors of Pharmacoepidemiology and Drug Safety recognize that most studies in pharmacoepidemiology cost money and thus pose a potential conflict of interest. As a conflict of interest may affect the assessment or judgment of an author, we ask that all authors (not just the Corresponding Author) complete the following form.

For Co-authors: Please complete questions 4-10. Completed forms should be saved, and emailed as an attachment to the Corresponding Author.

For Corresponding Authors: Please complete all questions. It is the responsibility of the Corresponding Author to submit completed forms on behalf of all co-authors via Manuscript Central at the point of manuscript submission.

\section{Corresponding author only (Co-authors go to Question 4):} POTENTIAL STUDY INTERPRETATION CONFLICTS

11. Some or all of the data that were used in this study were provided by a company with a vested interest in the product being studied.

$\mathrm{n} / \mathrm{a}$

12. The sponsor of this project had the right of commenting but the authors retained the right to accept or reject comments or suggestions.

$n / a$

13. The sponsor of this project had the right of final editing and/or approval of the manuscript submitted.

$\mathrm{n} / \mathrm{a}$

\section{Corresponding author and Co-authors:}

POTENTIAL FINANCIAL CONFLICTS

14. I, my spouse, or one of my dependent children is an employee of a company whose product is being studied.

No

15. I, my spouse, or one of my dependent children has significant equity interest (>USD 10,000) in the company that owns the product being studied.

No

16. In the past three years I have:

- been paid as a consultant (or in a similar capacity) by a company with a vested interest in the product being studied, on issues related to the product being studied;

No 
- been paid as a consultant (or in a similar capacity by a company with a vested interest in the product being studies, on issues unrelated to the product being studied; No

- received research or educational support from a company with a vested interest in the product(s) being studied.

17. A company whose product is being studied has provided funding to support the work on this project.

No

If you have answered YES to any of the above questions, or if you have additional personal, commercial or academic conflicts of interest, please draft a statement to publish with the article. e.g., $A B$ has been reimbursed by Safe Drug Ltd. for international conference attendance.

This study is funded by a Pfizer unrestricted educational grant.

18. Manuscript title (first six words are sufficient)

All-cause pneumonia in children after the introduction of pneumococcal vaccines in the United Kingdom: a population-based study

19. Author's full name (a separate form must be submitted for each author)

Wallis Cheuk Yin Lau

20. In checking this box, I confirm I have completed this form to the best of my knowledge. $\square$

This form is available online by clicking here 


\section{CONFLICT OF INTEREST DISCLOSURE}

The Editors of Pharmacoepidemiology and Drug Safety recognize that most studies in pharmacoepidemiology cost money and thus pose a potential conflict of interest. As a conflict of interest may affect the assessment or judgment of an author, we ask that all authors (not just the Corresponding Author) complete the following form.

For Co-authors: Please complete questions 4-10. Completed forms should be saved, and emailed as an attachment to the Corresponding Author.

For Corresponding Authors: Please complete all questions. It is the responsibility of the Corresponding Author to submit completed forms on behalf of all co-authors via Manuscript Central at the point of manuscript submission.

\section{Corresponding author only (Co-authors go to Question 4):} POTENTIAL STUDY INTERPRETATION CONFLICTS

21. Some or all of the data that were used in this study were provided by a company with a vested interest in the product being studied.

$\mathrm{n} / \mathrm{a}$

22. The sponsor of this project had the right of commenting but the authors retained the right to accept or reject comments or suggestions.

$n / a$

23. The sponsor of this project had the right of final editing and/or approval of the manuscript submitted.

\section{Corresponding author and Co-authors:}

POTENTIAL FINANCIAL CONFLICTS

24. I, my spouse, or one of my dependent children is an employee of a company whose product is being studied.

No

25. I, my spouse, or one of my dependent children has significant equity interest (>USD 10,000) in the company that owns the product being studied.

No

26. In the past three years I have:

- been paid as a consultant (or in a similar capacity) by a company with a vested interest in the product being studied, on issues related to the product being studied;

No 
- been paid as a consultant (or in a similar capacity by a company with a vested interest in the product being studies, on issues unrelated to the product being studied; No

- received research or educational support from a company with a vested interest in the product(s) being studied.

27. A company whose product is being studied has provided funding to support the work on this project.

No

If you have answered YES to any of the above questions, or if you have additional personal, commercial or academic conflicts of interest, please draft a statement to publish with the article. e.g., $A B$ has been reimbursed by Safe Drug Ltd. for international conference attendance.

This study is funded by a Pfizer unrestricted educational grant.

28. Manuscript title (first six words are sufficient)

All-cause pneumonia in children after the introduction of pneumococcal vaccines in the United Kingdom: a population-based study

29. Author's full name (a separate form must be submitted for each author)

Dr Julia Bielicki

30. In checking this box, I confirm I have completed this form to the best of my knowledge. $\square$

This form is available online by clicking here 


\section{CONFLICT OF INTEREST DISCLOSURE}

The Editors of Pharmacoepidemiology and Drug Safety recognize that most studies in pharmacoepidemiology cost money and thus pose a potential conflict of interest. As a conflict of interest may affect the assessment or judgment of an author, we ask that all authors (not just the Corresponding Author) complete the following form.

For Co-authors: Please complete questions 4-10. Completed forms should be saved, and emailed as an attachment to the Corresponding Author.

For Corresponding Authors: Please complete all questions. It is the responsibility of the Corresponding Author to submit completed forms on behalf of all co-authors via Manuscript Central at the point of manuscript submission.

\section{Corresponding author only (Co-authors go to Question 4):} POTENTIAL STUDY INTERPRETATION CONFLICTS

31. Some or all of the data that were used in this study were provided by a company with a vested interest in the product being studied.

$\mathrm{n} / \mathrm{a}$

32. The sponsor of this project had the right of commenting but the authors retained the right to accept or reject comments or suggestions.

$n / a$

33. The sponsor of this project had the right of final editing and/or approval of the manuscript submitted.

\section{Corresponding author and Co-authors:}

POTENTIAL FINANCIAL CONFLICTS

34. I, my spouse, or one of my dependent children is an employee of a company whose product is being studied.

No

35. I, my spouse, or one of my dependent children has significant equity interest (>USD 10,000) in the company that owns the product being studied.

No

36. In the past three years I have:

- been paid as a consultant (or in a similar capacity) by a company with a vested interest in the product being studied, on issues related to the product being studied;

No 
- been paid as a consultant (or in a similar capacity by a company with a vested interest in the product being studies, on issues unrelated to the product being studied; No

- $\quad$ received research or educational support from a company with a vested interest in the product(s) being studied.

37. A company whose product is being studied has provided funding to support the work on this project.

No

If you have answered YES to any of the above questions, or if you have additional personal, commercial or academic conflicts of interest, please draft a statement to publish with the article. e.g., $A B$ has been reimbursed by Safe Drug Ltd. for international conference attendance.

This study is funded by a Pfizer unrestricted educational grant.

38. Manuscript title (first six words are sufficient)

All-cause pneumonia in children after the introduction of pneumococcal vaccines in the United Kingdom: a population-based study

39. Author's full name (a separate form must be submitted for each author)

Chiara Tersigni

40. In checking this box, I confirm I have completed this form to the best of my knowledge. $\bigotimes$

This form is available online by clicking here 


\section{CONFLICT OF INTEREST DISCLOSURE}

The Editors of Pharmacoepidemiology and Drug Safety recognize that most studies in pharmacoepidemiology cost money and thus pose a potential conflict of interest. As a conflict of interest may affect the assessment or judgment of an author, we ask that all authors (not just the Corresponding Author) complete the following form.

For Co-authors: Please complete questions 4-10. Completed forms should be saved, and emailed as an attachment to the Corresponding Author.

For Corresponding Authors: Please complete all questions. It is the responsibility of the Corresponding Author to submit completed forms on behalf of all co-authors via Manuscript Central at the point of manuscript submission.

\section{Corresponding author only (Co-authors go to Question 4):} POTENTIAL STUDY INTERPRETATION CONFLICTS

41. Some or all of the data that were used in this study were provided by a company with a vested interest in the product being studied.

$\mathrm{n} / \mathrm{a}$

42. The sponsor of this project had the right of commenting but the authors retained the right to accept or reject comments or suggestions.

$n / a$

43. The sponsor of this project had the right of final editing and/or approval of the manuscript submitted.

\section{Corresponding author and Co-authors:}

POTENTIAL FINANCIAL CONFLICTS

44. I, my spouse, or one of my dependent children is an employee of a company whose product is being studied.

No

45. I, my spouse, or one of my dependent children has significant equity interest (>USD 10,000) in the company that owns the product being studied.

No

46. In the past three years I have:

- been paid as a consultant (or in a similar capacity) by a company with a vested interest in the product being studied, on issues related to the product being studied;

No 
- been paid as a consultant (or in a similar capacity by a company with a vested interest in the product being studies, on issues unrelated to the product being studied; No

- received research or educational support from a company with a vested interest in the product(s) being studied.

47. A company whose product is being studied has provided funding to support the work on this project. Yes

If you have answered YES to any of the above questions, or if you have additional personal, commercial or academic conflicts of interest, please draft a statement to publish with the article. e.g., $A B$ has been reimbursed by Safe Drug Ltd. for international conference attendance.

This study is funded by a Pfizer unrestricted educational grant.

48. Manuscript title (first six words are sufficient)

All-cause pneumonia in children after the introduction of pneumococcal vaccines in the United Kingdom: a population-based study

49. Author's full name (a separate form must be submitted for each author)

\section{Mike Sharland}

50. In checking this box, I confirm I have completed this form to the best of my knowledge. $\square$

This form is available online by clicking here 


\section{CONFLICT OF INTEREST DISCLOSURE}

The Editors of Pharmacoepidemiology and Drug Safety recognize that most studies in pharmacoepidemiology cost money and thus pose a potential conflict of interest. As a conflict of interest may affect the assessment or judgment of an author, we ask that all authors (not just the Corresponding Author) complete the following form.

For Co-authors: Please complete questions 4-10. Completed forms should be saved, and emailed as an attachment to the Corresponding Author.

For Corresponding Authors: Please complete all questions. It is the responsibility of the Corresponding Author to submit completed forms on behalf of all co-authors via Manuscript Central at the point of manuscript submission.

\section{Corresponding author only (Co-authors go to Question 4):} POTENTIAL STUDY INTERPRETATION CONFLICTS

51. Some or all of the data that were used in this study were provided by a company with a vested interest in the product being studied.

$\mathrm{n} / \mathrm{a}$

52. The sponsor of this project had the right of commenting but the authors retained the right to accept or reject comments or suggestions.

$n / a$

53. The sponsor of this project had the right of final editing and/or approval of the manuscript submitted.

\section{Corresponding author and Co-authors:}

POTENTIAL FINANCIAL CONFLICTS

54. I, my spouse, or one of my dependent children is an employee of a company whose product is being studied.

No

55. I, my spouse, or one of my dependent children has significant equity interest (>USD 10,000) in the company that owns the product being studied.

No

56. In the past three years I have:

- been paid as a consultant (or in a similar capacity) by a company with a vested interest in the product being studied, on issues related to the product being studied;

No 
- been paid as a consultant (or in a similar capacity by a company with a vested interest in the product being studies, on issues unrelated to the product being studied; No

- received research or educational support from a company with a vested interest in the product(s) being studied.

57. A company whose product is being studied has provided funding to support the work on this project. Yes

If you have answered YES to any of the above questions, or if you have additional personal, commercial or academic conflicts of interest, please draft a statement to publish with the article. e.g., $A B$ has been reimbursed by Safe Drug Ltd. for international conference attendance.

This study is funded by a Pfizer unrestricted educational grant. I also received educational grant from Pfizer in Hong Kong for an unrelated project.

58. Manuscript title (first six words are sufficient)

All-cause pneumonia in children after the introduction of pneumococcal vaccines in the United Kingdom: a population-based study

59. Author's full name (a separate form must be submitted for each author)

lan Chi Kei Wong

60. In checking this box, I confirm I have completed this form to the best of my knowledge. $\bigotimes$

This form is available online by clicking here 


\section{CONFLICT OF INTEREST DISCLOSURE}

The Editors of Pharmacoepidemiology and Drug Safety recognize that most studies in pharmacoepidemiology cost money and thus pose a potential conflict of interest. As a conflict of interest may affect the assessment or judgment of an author, we ask that all authors (not just the Corresponding Author) complete the following form.

For Co-authors: Please complete questions 4-10. Completed forms should be saved, and emailed as an attachment to the Corresponding Author.

For Corresponding Authors: Please complete all questions. It is the responsibility of the Corresponding Author to submit completed forms on behalf of all co-authors via Manuscript Central at the point of manuscript submission.

\section{Corresponding author only (Co-authors go to Question 4):} POTENTIAL STUDY INTERPRETATION CONFLICTS

61. Some or all of the data that were used in this study were provided by a company with a vested interest in the product being studied.

No

62. The sponsor of this project had the right of commenting but the authors retained the right to accept or reject comments or suggestions.

No

63. The sponsor of this project had the right of final editing and/or approval of the manuscript submitted.

\section{Corresponding author and Co-authors:}

POTENTIAL FINANCIAL CONFLICTS

64. I, my spouse, or one of my dependent children is an employee of a company whose product is being studied.

No

65. I, my spouse, or one of my dependent children has significant equity interest (>USD 10,000) in the company that owns the product being studied.

No

66. In the past three years I have:

- been paid as a consultant (or in a similar capacity) by a company with a vested interest in the product being studied, on issues related to the product being studied;

No 
- been paid as a consultant (or in a similar capacity by a company with a vested interest in the product being studies, on issues unrelated to the product being studied; No

- $\quad$ received research or educational support from a company with a vested interest in the product(s) being studied.

67. A company whose product is being studied has provided funding to support the work on this project.

No

If you have answered YES to any of the above questions, or if you have additional personal, commercial or academic conflicts of interest, please draft a statement to publish with the article. e.g., $A B$ has been reimbursed by Safe Drug Ltd. for international conference attendance.

This study is funded by a Pfizer unrestricted educational grant.

68. Manuscript title (first six words are sufficient)

All-cause pneumonia in children after the introduction of pneumococcal vaccines in the United Kingdom: a population-based study

69. Author's full name (a separate form must be submitted for each author)

\section{Professor Sonia Saxena}

70. In checking this box, I confirm I have completed this form to the best of my knowledge. $\square$

This form is available online by clicking here 


\section{TITLE PAGE}

Full Title: All-cause pneumonia in children after the introduction of pneumococcal vaccines in the United Kingdom: a population-based study

Running title: All-cause pneumonia in children after PCV introduction in UK

\section{Authors}

Wallis CY Lau ${ }^{1,2}$, Julia Bielicki ${ }^{3}$, Chiara Tersigni ${ }^{3}$, Sonia Saxena ${ }^{4}$, Ian C K Wong ${ }^{1,2}$, Mike Sharland ${ }^{3}$, Yingfen $\mathrm{Hsia}^{3}$

\section{Affiliations:}

1. Research Department of Practice and Policy, UCL School of Pharmacy, London, United Kingdom

2. Department of Pharmacology and Pharmacy, Li Ka Shing Faculty of Science, The University of Hong Kong, Hong Kong

3. Paediatric Infectious Disease Research Group, St George's University of London, United Kingdom

4. School of Public Health Imperial College London and Chartfield Surgery, United Kingdom.

\section{Corresponding author:}

Dr Yingfen Hsia

Institute for Infection and Immunity

Paediatric Infectious Disease Research Group

St. George's University of London

Jenner Wing, Level 2, Room 2.215E, Main Point J2C

London SW17 0RE

Tel: $+44(0) 2087254851$

Email: yhsia@sgul.ac.uk

Keywords: pneumococcal conjugate vaccine, pneumonia, children, primary care

\section{KEY POINTS}

- Incidence of childhood all-cause pneumonia declined by $37 \%$ in post-PCV era in UK. Incidence gradually declined in children aged $<2$ years after the introduction of PCV7. 
- During the two years after PCV13 introduction, no significant incidence reduction in children aged $<2$ (targeted population). A small incidence reduction in children aged 24 and 5-9 years in post-PCV13 era.

- A long-term monitoring would contribute to a better understanding of PCV13 effectiveness, as an increasing replacement of non-vaccine pneumococcal serotypes in carriage and diseases.

Word count: 2824

Sponsor of research: This study is funded by a Pfizer unrestricted educational grant. 


\begin{abstract}
Purpose: To explore the impact of PCVs in preventing childhood pneumonia in the United Kingdom.

Methods: We carried out a population-based study to assess the trend of all-cause pneumonia in children aged $<10$ years between 2002 and 2012. Data were obtained from the IMS Disease Analyzer, a primary care database in UK. Three time-periods were defined to estimate monthly incidence: pre-PCV7 (January 2002-August 2006), post-PCV7 (September 2006-March 2010), and post-PCV13 (April 2010-December 2012). Interrupted time series analysis (ITS) was performed to assess any immediate change or gradual change in the monthly incidence of pneumonia between pre- and post-vaccination introduction.
\end{abstract}

Results: A total of 4,228 children with at least one all-cause pneumonia episode were identified. The overall annual incidence rate of all-cause pneumonia declined by $37 \%$ from 3.8 episodes/1,000 person-years in 2002 to 2.4 episodes/1,000 person-years in 2012. Results of ITS analyses indicated that the incidence did not decline immediately after the introduction of PCV7 and PCV13. The incidence declined gradually in children aged $<2$ years (IRR $=0.98$; $95 \% \mathrm{CI}=0.97-0.99)$ post-PCV7, and levelled off during post-PCV13 (IRR=1.00; 95\% $\mathrm{CI}=0.99$ 1.02). No significant changes in incidence trend was observed in children aged 2-4 years $(\mathrm{IRR}=0.86 ; 95 \% \mathrm{CI}=0.68-1.07)$ and $5-9$ years $(\mathrm{IRR}=0.92 ; 95 \% \mathrm{CI}=0.73-1.15)$ after $\mathrm{PCV} 13$ introduction.

Conclusions: In the UK, the incidence of all-cause pneumonia in children $<2$ years declined after the introduction of PCV7 and levelled off in the first two years of introduction of PCV13. Continual monitoring is warranted to assess the population impact of PCV13 in preventing childhood pneumonia in the long-term. 


\section{INTRODUCTION}

Pneumonia is one of the most common infectious diseases in children. It is recognised to be an important public health issue worldwide because it causes considerable mortality in children. ${ }^{1}$ It has been estimated that approximately 156 million pneumonia cases occur each year, which account for approximately $15 \%$ (900,000 in 2015) of deaths in children aged under 5 years. ${ }^{2}$ In September 2016, PCV7 was introduced into UK childhood immunization program with a 2doses schedule at 2 and 4 months old and a booster after 12 months of age ( $2+1$ schedule), together with a 12-month catch-up campaign for all children aged $<2$ years. ${ }^{3}$ Studies have shown that the introduction of 7-valent pneumococcal conjugate vaccine (PCV7) significantly reduced the incidence of pneumonia in children. ${ }^{4-6}$ In the United States (US), a study reported a $43 \%$ reduction in the incidence of all-cause pneumonia hospitalisation in children aged under 2 years after PCV7 introduction. ${ }^{7}$ In the UK, a time-trend study of Hospital Episode Statistics (HES) data has shown a 19\% decrease of hospital admission rates for bacterial pneumonia in children aged $\leq 15$ years within the first two years after PCV7 introduction. ${ }^{8}$ However, an increase in non-vaccine serotypes in carriage led to replacement of PCV7 with a 13-valent vaccine (PCV13) in national immunisation schedule. In April 2010, PCV13 covering 6 additional pneumococcal serotypes $(1,3,5,6 \mathrm{~A}, 7 \mathrm{~F}$, and 19A) and replacing PCV7 was introduced into the UK immunisation program without a catch-up for older children. Several studies have reported a significant reduction of the incidence of pneumonia in children soon after the introduction of PCV13., ${ }^{7,-13}$ A recent study used Hospital Episodes Statistics (HES) data has shown a significant reduction of a composite of pneumococcal and unspecific cause pneumonia hospital admissions during post-PCV7 and PCV13 period in England, with approximately $34 \%$ reduction in children aged $<2$ years (targeted population). ${ }^{14}$ Most studies focused on hospitalisations and there is limited data reporting the impact of PCVs in preventing pneumonia in the community. Furthermore, the effect of PCV7 and PCV13 on childhood pneumonia has not been fully evaluated in the UK. We used a national primary care database to assess the incidence of all-cause childhood pneumonia and associated antibiotic prescribing over an 11-year period encompassing the introduction of PCV7 and PCV13 in the UK general practice. 


\section{METHODS}

\section{Study design}

We conducted a retrospective population-based study from $1^{\text {st }}$ January 2002 to $31^{\text {st }}$ December 2012 to estimate the incidence of all-cause childhood pneumonia and associated antibiotic prescribing from a UK primary care database. ${ }^{15}$

\section{Data source}

We used the IMS Disease Analyzer (IMS-DA), a longitudinal primary care database. The IMSDA contains medical records from nationally representative general practices in the UK (England, Wales, Scotland, and North Ireland). Around 125 general practices and more than 500 general practitioners (GPs) have agreed to contribute their patients' medical data to IMSDA. GPs use the computer software to enter patient medical records in their daily clinical practice for patient management. Information held on the database includes patient demographics, diagnosis, clinical symptoms, and prescriptions details. The data are then electronically transmitted from GPs' computer system to IMS-DA. The IMS-DA contains approximately 2 million anonymous patient records and over 95 million prescriptions. ${ }^{16}$ Diagnoses and clinical symptoms are coded using Read Clinical Terms, a hierarchical coding system. ${ }^{17,18}$ The Read codes are mapped to ICD-10 (International Statistical Classification Disease, $10^{\text {th }}$ Revision) terminology by IMS Health. Prescribed drugs are coded based on the Anatomical Therapeutic Chemical (ATC) classification issued by the European Pharmaceutical Market Research Association (EphMRA). ${ }^{19}$ IMS-DA has previously used to study impact of PCVs on childhood otitis media in the UK. ${ }^{15}$

\section{Identification of all-cause pneumonia episode and associated antibiotic prescribing}

We included all children aged 10 years or younger during the study period and registered with a general practice for at least 6 months. Children temporarily registered with a general practice were excluded to ensure that there was no duplication of the same patients being permanently registered at another participating general practice. Read code lists for pneumonia were developed by clinical epidemiologists, including a GP (SS) and 2 paediatric consultants (JB, MS). The Read code list for all-cause pneumonia is presented in Supplement Table 1. A 28day screening period was set from each episode, and any subsequent episode within the screening period were classified as follow-up visits for the same episodes; the first pneumonia episode that was more than 28 days apart from the previous episode after this period was again 
counted as an incident episode. The main advantage of IMS-DA over other UK primary care databases is that, in the IMS-DA database, prescriptions are directly linked to a diagnosis by the GP at the time of consultation ${ }^{20}$. Children were classified as "treated" if they had an antibiotic prescription on the same date as a pneumonia episode was recorded. Prescribed drugs are coded based on the ATC classification. Antibiotics were defined based on the therapeutic level ATC-J01.

\section{Secular trends}

We estimated the annual and monthly incidence of all-cause pneumonia between 2002 and 2012. The annual incidence rate was defined as the total number of episodes during the study period divided by the total person-years of the study population during the time period. The monthly incidence rate was defined as total number of episodes during each month divided by the total person-months of the study population. Age-specific incidence rates were calculated for the following age groups: aged $<2$ years, 2-4 years, and 5-9 years. The 95\% confidence intervals (CI) were estimated based on Poisson distribution.

\section{Interrupted time series analysis}

We used a segmented regression model of an Interrupted Time Series (ITS) to investigate the change of all-cause pneumonia incidence rate before and after the introduction of PCV7 and PCV13. ${ }^{21,22}$ Poisson regression was used in the ITS analysis. Over-dispersion were checked using the likelihood ratio test of over-dispersion parameter by running the same regression model using negative binomial distribution. The ITS model included two standard effect size measures: a change in level and a change in trend. A change in level indicates the difference between the incidence of pneumonia at the post-PCV time period and the predicted incidence extrapolated from the pre-PCV trends (i.e. an abrupt change immediately after intervention), whereas a change in trend is defined as the difference between the slopes in pneumonia incidences during the post- and pre-intervention period (i.e. a gradual change after intervention). Three time-periods were defined to estimate monthly incidence: pre-PCV7 (January 2002-August 2006), post-PCV7 (September 2006-March 2010), and post-PCV13 (April 2010-December 2012). The change in level and change in trend were assessed for both pre-post PCV7 and pre-post PCV13 periods. As such, the changes for pre-post PCV7 refers to the comparison between post-PCV7 and pre-PCV7; whereas the changes for pre-post PCV13 refers to the comparison between post-PCV13 and pre-PCV13 (including the post-PCV7-prePCV13 period). As there were strong seasonal fluctuations for seasonal variation where 
pneumonia rates were significantly higher in the winter months than in the summer, the model was adjusted for seasonality by adding an indicator for specific calendar months in the model. ${ }^{21,22} \mathrm{We}$ accounted for first-order autocorrelation in our models given that the error terms of consecutive data points are often correlated with each other. ${ }^{21}$ Residual analyses were conducted and final models showed no evidence of autocorrelations. Data management and analyses were performed using Stata SE software version 14.0 (Stata Corp., College Station, TX, USA) and Statistical Analysis System (SAS) v9.3 (SAS Inc., United States).

\section{RESULTS}

Over the 11-year study period, a total of 8,148 all-cause pneumonia episodes were identified in 4,228 children $(54.8 \%$ male; $2,317 / 4,228)$. The median age at pneumonia diagnosis was 3 years (interquartile range [IQR]: 2-5 years). Overall, 37.0\% $(1,565 / 4,228)$ of children had only one all-cause pneumonia episode during the study period. A total of 1,815 antibiotic prescriptions were prescribed to 907 children during the study period, thus about $21 \%$ $(907 / 4,228)$ of children with pneumonia received antibiotic treatment.

\section{All-cause pneumonia}

The annual incidence rate of all-cause pneumonia in children aged $<10$ years declined by $37 \%$ from 3.8 episodes/1,000 person-years $(95 \% \mathrm{CI}, 3.6-4.0)$ in 2002 to 2.4 episodes/1,000 personyears $(95 \% \mathrm{CI}, 2.2-2.7)$ in 2012 . The highest incidence rate of all-cause pneumonia was observed in children aged $<2$ years, followed by 2-4 years and 5-9 years (Table 1). The incidence of pneumonia was strongly related to season, with higher rates observed in winter months compared to other months (Figure 1). The overall monthly incidence by age group is presented in Figure 2. The seasonal variation was also observed in age groups. Overall, the monthly incidence rates were lower in all age groups during post-PCV period compared to prePCV period. Before the introduction of PCV7, the incidence of pneumonia was increasing gradually by $0.6 \%$ per month $(95 \% \mathrm{CI}=0.2 \%-0.9 \%)$ in children aged $<2$ years; $0.5 \%$ per month $(95 \% \mathrm{CI}=0.2 \%-0.8 \%)$ in children aged $2-4$ years; and $0.5 \%$ per month $(95 \% \mathrm{CI}=0.1 \%-0.8 \%)$ in children aged 5-9 years. After the introduction of PCV7, there was no immediate reduction in the incidence of pneumonia in children aged $<2$ years (incidence rate ratio [IRR] $=1.04$; $95 \% \mathrm{CI}=0.86-1.24)$. However, the incidence of pneumonia then declined gradually over the post-PCV7 period (IRR $=0.98 ; 95 \% \mathrm{CI}=0.97-0.99)$. Similarly, there was a gradual decline in the trend in pneumonia incidence during the post-PCV7 period in children aged 2-4 years $(I R R=0.99 ; 95 \% C I=0.98-0.99)$ and $5-9$ years $(I R R=0.99 ; 95 \% C I=0.99-1.00)$. Following the 
introduction of PCV13, no immediate change in pneumonia incidence was observed in children aged $<2$ years $(\mathrm{IRR}=1.09 ; 95 \% \mathrm{CI}=0.81-1.49), 2-4$ years $(\mathrm{IRR}=0.86 ; 95 \% \mathrm{CI}=0.68-1.07)$, and $5-9$ years $(\mathrm{IRR}=0.92 ; 95 \% \mathrm{CI}=0.73-1.15)$. There was no subsequent change in the trend in pneumonia incidence over the post-PCV13 period for all age groups (Table 2).

\section{Antibiotic prescription rates for all-caused pneumonia treatment}

Overall, antibiotic prescribing rates for all-cause pneumonia decreased by $23 \%$, from 0.70 prescriptions/1,000 person-years $(95 \% \mathrm{CI} 0.60-0.82)$ in 2002 to 0.54 prescriptions/1,000 person-years $(95 \% \mathrm{CI}$ 0.44-0.68) in 2012. The antibiotics prescribed for all-cause pneumonia were consistent during the study period (Supplement Figure 1). Amoxicillin was the most commonly prescribed antibiotic, accounting for $60.3 \%-73.2 \%$ of pneumonia-associated prescriptions annually, followed by erythromycin (18.4\%-4.7\%) and co-amoxiclav (8.6\%9.3\%). A seasonal variation was also observed for antibiotic pneumonia treatment with higher rates in winter months compared with other months.

\section{DISCUSSION}

The national coverage of PCV7 was over $90 \%$ in children before the introduction of PCV13. After 12 months of PCV13 implementation, the coverage was $94.6 \%$ in children aged 1 year and $92 \%$ in children aged 2 years. ${ }^{23}$ Despite high vaccine coverage in our study population, we did not observe a substantial reduction for the community pneumonia incidence in the target population of young children aged $<2$ years or preschool children aged 2-4 years in postPCV13 period. Although a numerically lower incidence of pneumonia was seen in children aged 2-4 and 5-9 years soon after the introduction of PCV13, the confidence intervals include 1.0. As the conjugate vaccines prevent carriage, targeting the initial PCV7 program to the agegroup with the highest pneumococcal carriage rates $(<2$ year olds) could have resulted in indirect (herd) protection through reduced transmission of pneumococcal vaccine serotypes to unvaccinated and older children and adults. Since the indirect protection lags behind direct protection, any continuing decline in pneumonia incidence in children aged 2-4 and 5-9 years even after PCV13 introduction would likely be due to a combination of vaccinated cohorts getting older and the indirect protection offered to the older, unvaccinated age groups. We found antibiotics prescribed for children with pneumonia are in accordance with treatment recommendations in the British National Formulary for Children (BNFC), with amoxicillin being the predominant antibiotic of choice. ${ }^{24}$ 


\section{Comparison with previous literature}

Previous studies have shown that the impact of PCV on all-cause pneumonia was age-related: the most substantial reduction was in children aged $<2$ years. In addition, a strong association of PCV13 with a reduction of pneumonia admission in the post-PCV13 era has been reported throughout the world. ${ }^{9-13}$ Our results showed that the incidence of all-cause childhood pneumonia in the community decreased gradually after the introduction of PCV7 but did not continue to decline after the introduction of PCV13. Similarly, a recent study using HES data in England also reported a significant reduction on pneumonia hospital admission during postPCV7 period in English children aged $<16$ years but the admission rates increased slightly soon after the PCV13 introduction. ${ }^{25}$ The results from the present study and the HES data study in England contrast with previous studies outside the UK. One explanation is the incidence of pneumonia varies between regions being influenced by local circulating strains and the level of antibiotic use. ${ }^{26,27}$ This will consequently affect PCV effectiveness across countries. Further, most previous studies focused on hospital admissions but in general, a direct comparison between the effects of PCV on pneumonia hospitalisations and on all-cause pneumonia incidence in the community is difficult.

Another recent study used HES data to compare the incidence of pneumonia (pneumococcal pneumonia and/or unspecified cause pneumonia) during two study periods: Apr 2004 - Mar 2006 and Apr 2013 - Mar 2015. ${ }^{14}$ The study reported that about 34\% of incidence reduction was observed in children aged $<2$ years. However, the analysis did not account for the trend of pneumonia between Apr 2006 and Mar 2013, during which PCV7 and PCV13 were introduced. Thus, it's unclear whether the decline in incidence was brought by PCV7 alone, PCV13 alone, or both. The authors acknowledged that they did not evaluate the impact of PCV7 and PCV13 separately. In contrast, our study looked into the effects of PCV7 and PCV13 individually, and our results showed that there was a significant decline in pneumonia after the introduction of PCV7; our results further showed that the decline had levelled off after the introduction of PCV13. Also, while HES contains data from hospitals in England only, IMS DA contains data from community setting across UK (England, Scotland, Wales, Ireland). Therefore, the present study addressed the limitations of the previous literatures, and our results raised the need for continual monitoring on the population impact of PCV13 on childhood pneumonia in both hospitals and community. 


\section{Strength and limitations}

To our knowledge, this is the first UK-wide study to investigate the impact of both PCV7 and PCV13 on all-cause childhood pneumonia in the community. The strength of this study is the generalizability and representative coverage of patients attending GP practices across the UK (England, Scotland, Wales, and Northern Ireland). However, there are several limitations of this study. First, we do not have pneumococcal serotype data and culture results for pneumonia cases. Microbiological samples are rarely obtained from patients presenting to primary care. This is a general limitation in administrative databases in the UK. As the laboratory data and culture results are not available, we were unable to investigate whether the frequency of Streptococcus pneumoniae isolation changed in present study. Thus, it's problematic to estimate the proportion of pneumonia which may be pneumococcal in primary care database.

Second, there was no X-ray or other laboratory information in IMS-DA to confirm the pneumonia diagnosis. Third, this is an ecological study of the effect of pneumococcal vaccines on all-cause pneumonia rates, and we cannot directly attribute the observed reductions to PCV introduction. In addition, we were unable to assess how other factors (e.g. influenza rate) affect pneumonia rate. Fourth, our primary care data did not link with secondary care records so pneumonia cases who only presented to hospitals would have been missed. For the same reason, the antibiotic prescribing rates for pneumonia treatment may be underestimated in our study as no antibiotic prescriptions issued for pneumonia treatment for patients only admitted to hospitals were included. Fifth, there is a potential for misclassification bias when using diagnostic codes to define pneumonia in administrative databases. Clinicians may prefer certain diagnostic codes over others to support their clinical decision. The code choice for analysis could potentially influence absolute counts and, possibly, age distribution of cases, and such biases could affect the estimate of PCV effectiveness in the community setting. Although we did not conduct a validation study to verify diagnostic codes for all-cause pneumonia, the codes used were similar to previous studies using the Read code system to identify pneumonia cases in the UK. ${ }^{3,28}$ Finally, we have limited follow-up time after the introduction PCV13 in our study.

\section{Implications and future research}

We assessed the first 2 years of PCV13 use in our study population. In order to fully evaluate the benefit of PCV13 in preventing pneumonia, on-going surveillance data from both primary care and secondary care are required. Notably, a recent study using pneumococcal disease surveillance data has reported an increased incidence of invasive pneumococcal disease in 
children aged $<5$ years between 2012/13 and 2013/14 in the UK. ${ }^{29}$ Also, an over 20\% increase of non-PCV13 serotypes was observed within 4 years after PCV13 replaced PCV7. This warrants long-term monitoring of the effectiveness of PCV13 in preventing pneumonia in children.

\section{CONCLUSION}

This is the first study to investigate the impact of PCV7 and PCV13 on community childhood pneumonia in the UK. Our data did not show a continual reduction in pneumonia consultations in vaccine-eligible children following the introduction of PCV13. An on-going monitoring would contribute to a better understanding of PCV13 effectiveness, accounting for potentially increasing replacement of non-vaccine pneumococcal serotypes in carriage and diseases.

\section{ETHICS STATEMENT}

This study protocol was approved by the IMS Independent Scientific and Ethical Advisory Committee.

\section{CONFLICT OF INTEREST}

None declared.

\section{FINANCIAL DISCLOSURES}

This study is funded by a Pfizer unrestricted educational grant. Professor Sonia Saxena was funded by a National Institute for Health Research Career Development Fellowship (NIHR CDF-2011-04-048). This article presents independent research commissioned by the National Institute for Health Research (NIHR) under the Collaborations for Leadership in Applied Health Research and Care (CLAHRC) programme for North West London. The views expressed in this publication are those of the authors and not necessarily those of the NHS, the NIHR or the Department of Health.

\section{AUTHORS' CONTRIBUTION}

YH and WL have full access to the data and take responsibility for the accuracy of data analysis. MS, IW, SS, YH conceptualized and designed the study. SS and BJ developed code lists for data extraction. $\mathrm{CT}, \mathrm{YH}$, and WL carried out data analyses and drafted the initial manuscript. All authors participated in data interpretation and critically reviewed the manuscript and approved the final manuscript as submitted. 
Figure 1 Monthly incidence rates of all-cause pneumonia and associated antibiotic prescribing in children aged $<10$ years

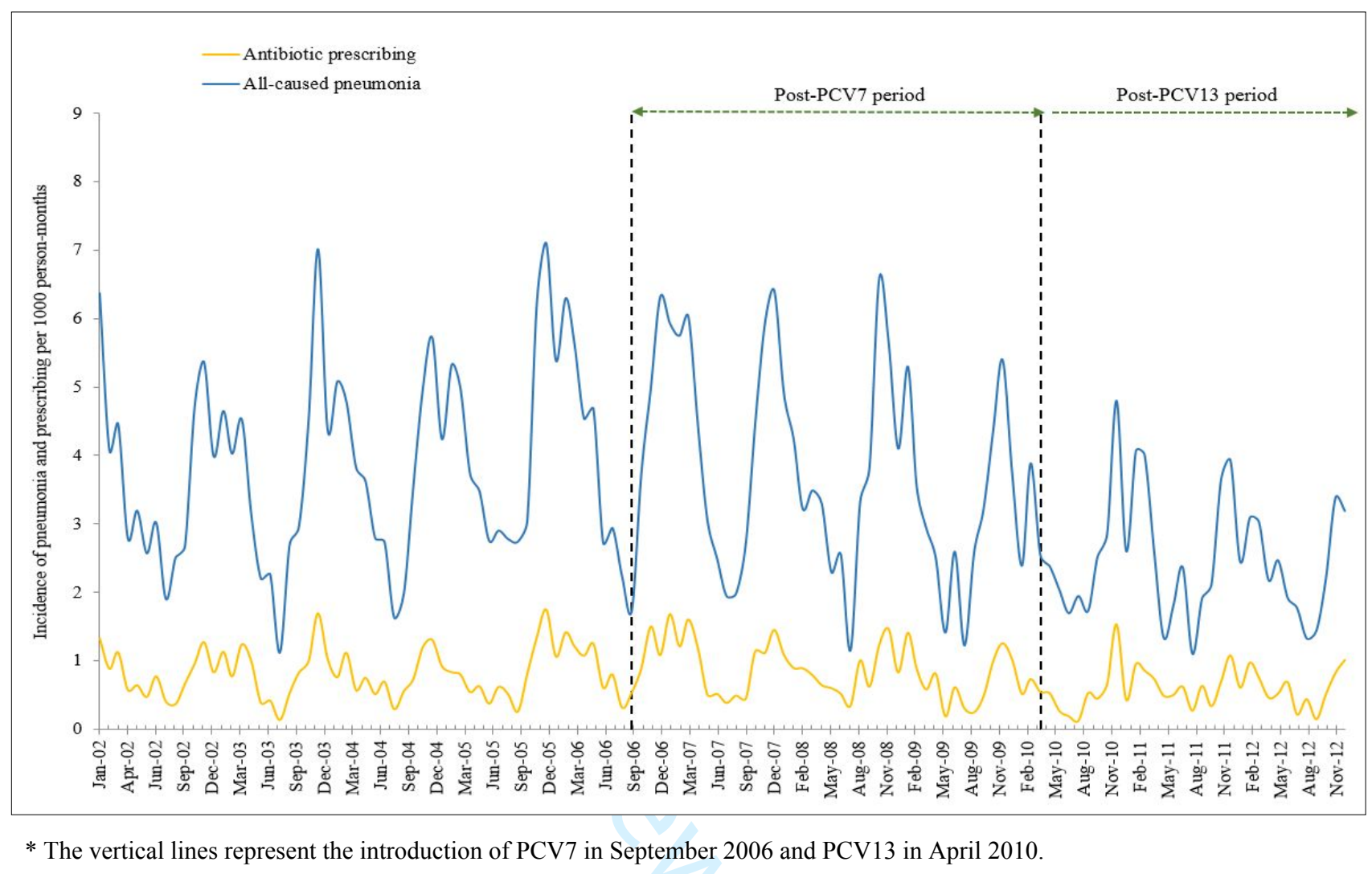


Figure 2 Monthly incidence of all-cause pneumonia by age groups, 2002-2012

2
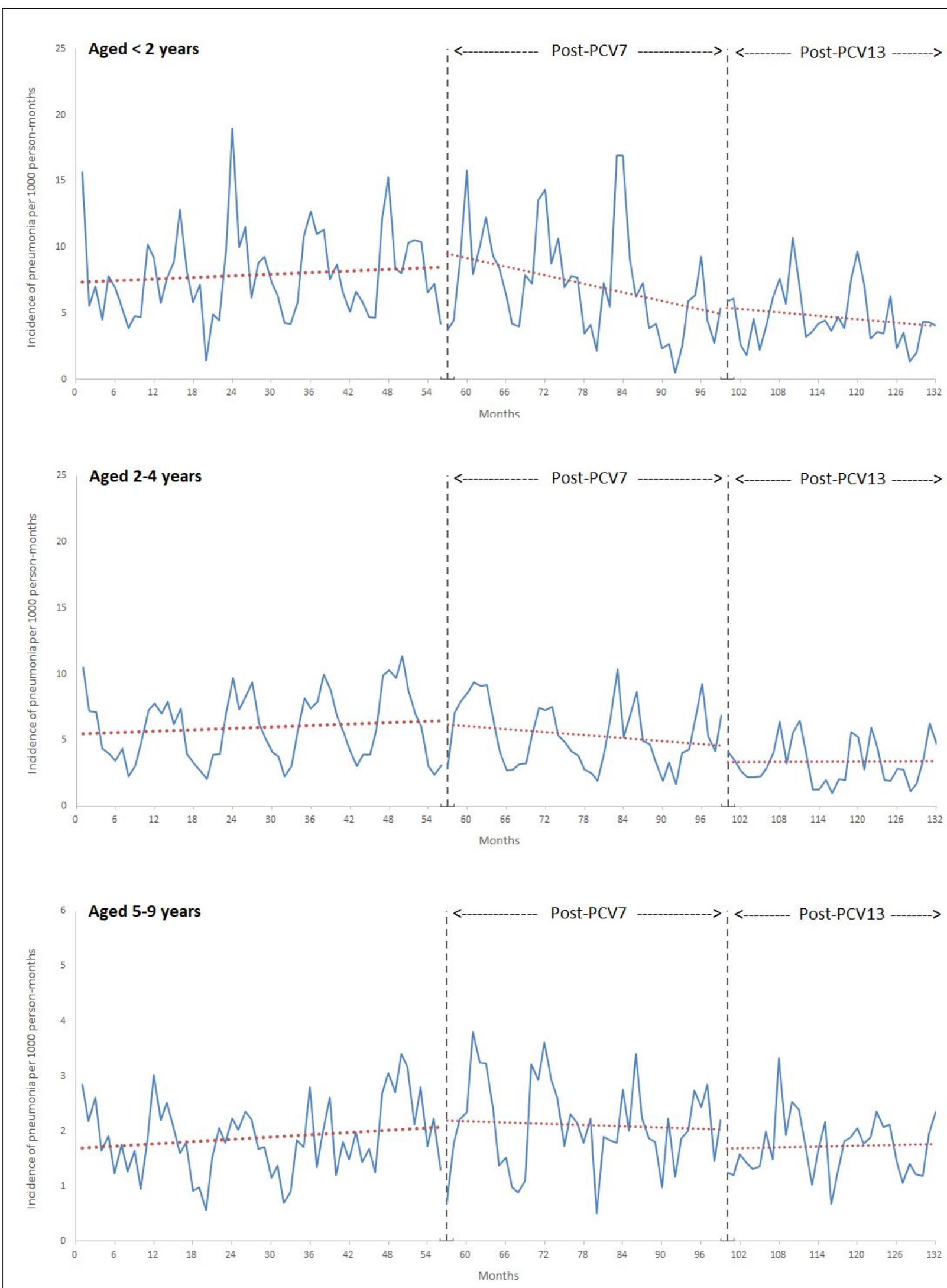
Table 1 Annual incidence rates (with 95\% confidence interval) for all-cause pneumonia in children aged $<10$ years

\begin{tabular}{|c|c|c|c|c|c|c|c|c|c|c|c|}
\hline & 2002 & 2003 & 2004 & 2005 & 2006 & 2007 & 2008 & 2009 & 2010 & 2011 & 2012 \\
\hline Overall & $3.8(3.6-4.0)$ & $3.7(3.5-4.0)$ & $3.9(3.6-4.1)$ & $4.2(3.9-4.5)$ & $4.3(4.1-4.6)$ & $4.3(4.0-4.6)$ & $3.8(3.5-4.0)$ & $3.3(3.0-3.6)$ & $2.7(2.5-3.0)$ & $2.6(2.4-2.9)$ & $2.4(2.2-2.7)$ \\
\hline \multicolumn{12}{|l|}{ Sex } \\
\hline Boys & $4.2(3.8-4.5)$ & $4.1(3.7-4.5)$ & $4.0(3.7-4.4)$ & $4.7(4.3-5.1)$ & $4.4(4.0-4.8)$ & $4.5(4.1-4.9)$ & $4.0(3.7-4.5)$ & $3.5(3.1-3.9)$ & $2.7(2.4-3.1)$ & $2.8(2.5-3.2)$ & $2.6(2.2-3.0)$ \\
\hline Girls & $3.4(3.1-3.7)$ & $3.3(3.0-3.7)$ & $3.7(3.3-4.0)$ & $3.7(3.3-4.0)$ & $4.3(3.9-4.7)$ & $4.1(3.8-4.6)$ & $3.5(3.1-3.9)$ & $3.1(2.7-3.4)$ & $2.8(2.4-3.1)$ & $2.5(2.1-2.8)$ & $2.2(1.9-2.6)$ \\
\hline \multicolumn{12}{|l|}{ Age (year) } \\
\hline$<2$ & $7.2(6.3-8.3)$ & $8.4(7.4-9.5)$ & $8.2(7.2-9.3)$ & $8.5(7.4-9.6)$ & $8.4(7.4-9.6)$ & $9.1(8.0-10.3)$ & $8.6(7.5-9.8)$ & $5.1(4.2-6.1)$ & $4.6(3.7-5.7)$ & $5.7(4.7-7.0)$ & $3.8(2.9-4.9)$ \\
\hline $2-4$ & $5.7(5.2-6.3)$ & $5.6(5.0-6.1)$ & $6.0(5.5-6.6)$ & $6.8(6.2-7.4)$ & $6.6(5.9-7.2)$ & $5.9(5.3-6.5)$ & $5.0(4.5-5.6)$ & $5.0(4.4-5.6)$ & $4.0(3.4-4.5)$ & $3.3(2.8-3.9)$ & $3.4(2.9-4.0)$ \\
\hline $5-9$ & $2.0(1.8-2.3)$ & $1.8(1.5-2.0)$ & $1.8(1.5-2.0)$ & $1.9(1.7-2.2)$ & $2.3(2.0-2.5)$ & $2.4(2.1-2.7)$ & $2.1(1.8-2.4)$ & $2.1(1.8-2.4)$ & $1.8(1.6-2.1)$ & $1.8(1.2-2.1)$ & $1.8(1.5-2.0)$ \\
\hline
\end{tabular}

7 
Table 2 Interrupted time series analysis of monthly incidence rate for all-cause pneumonia by age groups

\begin{tabular}{|c|c|c|c|c|}
\hline \multirow[t]{2}{*}{ Parameter/age group } & \multicolumn{2}{|c|}{ PCV7 } & \multicolumn{2}{|c|}{ PCV13 } \\
\hline & IRR $(95 \% \mathrm{CI})$ & $\mathrm{P}$ value & IRR $(95 \% \mathrm{CI})$ & $\mathrm{P}$ value \\
\hline \multicolumn{5}{|l|}{ Aged $<2$ years } \\
\hline Change in level (immediate effect) & $1.04(0.86-1.24)$ & 0.71 & $1.09(0.81-1.49)$ & 0.57 \\
\hline Change in trend post-intervention & $0.98(0.97-0.99)$ & $<0.001$ & $1.00(0.99-1.02)$ & 0.98 \\
\hline \multicolumn{5}{|l|}{ Aged $2-4$ years } \\
\hline Change in level (immediate effect) & $0.89(0.77-1.03)$ & 0.11 & $0.86(0.68-1.07)$ & 0.17 \\
\hline Change in trend post-intervention & $0.99(0.98-0.99)$ & $<0.001$ & $1.00(0.99-1.01)$ & 0.68 \\
\hline \multicolumn{5}{|l|}{ Aged 5-9 years } \\
\hline Change in level (immediate effect) & $1.02(0.86-1.21)$ & 0.80 & $0.92(0.73-1.15)$ & 0.47 \\
\hline Change in trend post-intervention & $0.99(0.99-1.00)$ & 0.03 & $1.00(0.99-1.01)$ & 0.81 \\
\hline
\end{tabular}

$0.99(0.99-1.00)$

$1.92(0.73-1.15)$

0.81 


\section{References}

1. Wardlaw TMJ, Emily White; Hodge, Matthew; World Health Organization; UNICEF. Pneumonia: the forgotten killer of children. http://appswhoint/iris/bitstream/handle/10665/43640/9280640489 engpdf?sequence =1 (Accessed May 2018).

2. Rudan I, Boschi-Pinto C, Biloglav Z, Mulholland K, Campbell H. Epidemiology and etiology of childhood pneumonia. Bull World Health Organ. 2008;86(5):408-416.

3. Millett ER, Quint JK, Smeeth L, Daniel RM, Thomas SL. Incidence of communityacquired lower respiratory tract infections and pneumonia among older adults in the United Kingdom: a population-based study. PLoS One. 2013;8(9):e75131.

4. Grijalva CG, Nuorti JP, Arbogast PG, Martin SW, Edwards KM, Griffin MR. Decline in pneumonia admissions after routine childhood immunisation with pneumococcal conjugate vaccine in the USA: a time-series analysis. Lancet. 2007;369(9568):11791186.

5. Grijalva CG, Nuorti JP, Zhu Y, Griffin MR. Increasing incidence of empyema complicating childhood community-acquired pneumonia in the United States. Clin Infect Dis. 2010;50(6):805-813.

6. Jardine A, Menzies RI, McIntyre PB. Reduction in hospitalizations for pneumonia associated with the introduction of a pneumococcal conjugate vaccination schedule without a booster dose in Australia. Pediatr Infect Dis J. 2010;29(7):607-612.

7. Griffin MR, Mitchel E, Moore MR, et al. Declines in pneumonia hospitalizations of children aged $<2$ years associated with the use of pneumococcal conjugate vaccines Tennessee, 1998-2012. MMWR Morb Mortal Wkly Rep. 2014;63(44):995-998.

8. Koshy E, Murray J, Bottle A, Sharland M, Saxena S. Impact of the seven-valent pneumococcal conjugate vaccination (PCV7) programme on childhood hospital admissions for bacterial pneumonia and empyema in England: national time-trends study, 1997-2008. Thorax. 2010;65(9):770-774.

9. Angoulvant F, Levy C, Grimprel E, et al. Early impact of 13-valent pneumococcal conjugate vaccine on community-acquired pneumonia in children. Clin Infect Dis. 2014;58(7):918-924.

10. Berglund A, Ekelund M, Fletcher MA, Nyman L. All-cause pneumonia hospitalizations in children $<2$ years old in sweden, 1998 to 2012: impact of pneumococcal conjugate vaccine introduction. PLoS One. 2014;9(11):e112211.

11. Greenberg D, Givon-Lavi N, Ben-Shimol S, Ziv JB, Dagan R. Impact of PCV7/PCV13 introduction on community-acquired alveolar pneumonia in children $<5$ years. Vaccine. 2015;33(36):4623-4629.

12. Hortal M, Estevan M, Meny M, Iraola I, Laurani H. Impact of pneumococcal conjugate vaccines on the incidence of pneumonia in hospitalized children after five years of its introduction in Uruguay. PLoS One. 2014;9(6):e98567.

13. Simonsen L, Taylor RJ, Schuck-Paim C, Lustig R, Haber M, Klugman KP. Effect of 13-valent pneumococcal conjugate vaccine on admissions to hospital 2 years after its introduction in the USA: a time series analysis. Lancet Respir Med. 2014;2(5):387-394.

14. Thorrington D, Andrews N, Stowe J, Miller E, van Hoek AJ. Elucidating the impact of the pneumococcal conjugate vaccine programme on pneumonia, sepsis and otitis media hospital admissions in England using a composite control. BMC Med. 2018;16(1):13.

15. Lau WC, Murray M, El-Turki A, et al. Impact of pneumococcal conjugate vaccines on childhood otitis media in the United Kingdom. Vaccine. 2015;33(39):5072-5079.

16. Wong IC, Murray ML. The potential of UK clinical databases in enhancing paediatric medication research. Br J Clin Pharmacol. 2005;59(6):750-755.

17. Booth N. What are the Read Codes? Health Libr Rev. 1994;11(3):177-182. 
18. Chisholm J. The Read clinical classification. BMJ. 1990;300(6732):1092.

19. Association EPMR. European Pharmaceutical Market Research Association. ATCAnatomical classification. http://wwwephmraorg/anatomical-classification. Accessed June 2018.

20. Hsia Y, Dawoud D, Sutcliffe AG, Viner RM, Kinra S, Wong IC. Unlicensed use of metformin in children and adolescents in the UK. $\mathrm{Br} J$ Clin Pharmacol. 2012;73(1):135-139.

21. Wagner AK, Soumerai SB, Zhang F, Ross-Degnan D. Segmented regression analysis of interrupted time series studies in medication use research. J Clin Pharm Ther. 2002;27(4):299-309.

22. Bernal JL, Cummins S, Gasparrini A. Interrupted time series regression for the evaluation of public health interventions: a tutorial. Int J Epidemiol. 2017;46(1):348355.

23. Official statistics Ns. NHS Immunisation Statistics-England, 2011-12. https://digitalnhsuk/data-and-information/publications/statistical/nhs-immunisationstatistics/nhs-immunisation-statistics-england-2011-12. Accessed June 2018.

24. Committee P. BNF for Children 2017. London: BMJ Group, Pharmaceutical Press, and RCPCH Publications. 2015.

25. Saxena S, Atchison C, Cecil E, Sharland M, Koshy E, Bottle A. Additive impact of pneumococcal conjugate vaccines on pneumonia and empyema hospital admissions in England. J Infect. 2015;71(4):428-436.

26. Fletcher MA, Schmitt HJ, Syrochkina M, Sylvester G. Pneumococcal empyema and complicated pneumonias: global trends in incidence, prevalence, and serotype epidemiology. Eur J Clin Microbiol Infect Dis. 2014;33(6):879-910.

27. Zuccotti G, Mameli C, Daprai L, et al. Serotype distribution and antimicrobial susceptibilities of nasopharyngeal isolates of Streptococcus pneumoniae from healthy children in the 13-valent pneumococcal conjugate vaccine era. Vaccine. 2014;32(5):527-534.

28. Myles PR, McKeever TM, Pogson Z, Smith CJ, Hubbard RB. The incidence of pneumonia using data from a computerized general practice database. Epidemiol Infect. 2009;137(5):709-716.

29. Ladhani SN, Collins S, Djennad A, et al. Rapid increase in non-vaccine serotypes causing invasive pneumococcal disease in England and Wales, 2000-17: a prospective national observational cohort study. Lancet Infect Dis. 2018;18(4):441-451. 

Analyze (IMS-DA), 2002-2012

\begin{tabular}{|c|c|c|}
\hline Read code & Description & Total episodes \\
\hline H062. & Acute low respiratory tract infection & 1,492 \\
\hline $\mathrm{H} 2 \ldots$ & Pneumonia and influenza & 1,403 \\
\hline $\mathrm{H} 21 .$. & Lobar (pneumococcal) pneumonia & 1,067 \\
\hline H26.. & Pneumonia, organism unspecific. & 881 \\
\hline $\mathrm{H} 2 \mathrm{z} .$. & Pneumonia or influenza NOS & 845 \\
\hline $\mathrm{H} 25 .$. & Bronchopneumonia, organism unspecific & 778 \\
\hline $\mathrm{H} 20 .$. & Viral pneumonia & 277 \\
\hline $\mathrm{H} 28 .$. & Atypical pneumonia & 261 \\
\hline H260. & Lobar pneumon-unspec organism & 198 \\
\hline $\mathrm{H} 22 .$. & Other bacterial pneumonia & 171 \\
\hline .H3.. & Pneumonia and influenza & 149 \\
\hline $\mathrm{H} 2600$ & Lung consolidation & 76 \\
\hline $\mathrm{H} 22 \mathrm{z}$. & Bacterial pneumonia NOS & 69 \\
\hline H33. & Bronchopneumonia & 69 \\
\hline $\mathrm{H} 231$. & Pneumonia-mycoplasma pneumon & 68 \\
\hline H23.. & Pneumonia - specific organisms & 41 \\
\hline H2y.. & Pneumonia or influenza OS & 39 \\
\hline H223. & Pneumonia - streptococcal & 39 \\
\hline .H32. & Lobar-pneumococcal-pneumonia & 32 \\
\hline H34. & Pneumonia NOS & 28 \\
\hline H261. & Basal pneumon-unspecific organism & 26 \\
\hline H201. & Pneumonia - resp.syncyt.virus & 18 \\
\hline H34Z & Pneumonia NOS & 18 \\
\hline $\mathrm{H} 20 \mathrm{z}$. & Viral pneumonia NOS & 12 \\
\hline .H31. & Viral pneumonia & 10 \\
\hline H56y1 & Interstitial pneumonia & 9 \\
\hline $\mathrm{H} 23 \mathrm{z}$. & Pneumonia - specific organism NOS & 9 \\
\hline H060A & Ac bronch/mycoplasma pneumonia & 7 \\
\hline A3BXA & Mycopl pneu [PPLO] c ds c/o c & 6 \\
\hline $\mathrm{H} 24 .$. & Pneumonia + Infect.disease EC & 6 \\
\hline H243. & Pneumonia + whooping cough & 5 \\
\hline $\mathrm{H} 200$. & Pneumonia - adenovirus & 4 \\
\hline $\mathrm{H} 346$ & Bilateral pneumonia & 3 \\
\hline $\mathrm{H} 220$. & Pneumonia - klebsiella pneum. & 3 \\
\hline H5302 & Chlamydial pneumonia & 2 \\
\hline $\mathrm{H} 2700$ & Influenza + bronchopneumonia & 2 \\
\hline
\end{tabular}




\begin{tabular}{|l|l|c|}
\hline H270. & Influenza + pneumonia & 2 \\
\hline H24y7 & Pneumonia + varicella & 2 \\
\hline H222. & Pneumonia - H.influenzae & 2 \\
\hline H5303 & Abscess of lung with pneumonia & 1 \\
\hline H233. & Chlamydial pneumonia & 1 \\
\hline A7893 & HIV dis,res Pneumocys carin pn & 1 \\
\hline H240. & Pneumonia + measles & 1 \\
\hline H24y2 & Pneumonia + pneumocyst.carinii & 1 \\
\hline H202. & Pneumonia - parainfluen.virus & 1 \\
\hline H221. & Pneumonia - pseudomonas & 1 \\
\hline H224. & Pneumonia - staphylococcal & 1 \\
\hline H20y. & Pneumonia - virus NEC & 1 \\
\hline H2230 & Pneumonia due/streptococc,gp B & 1 \\
\hline H3Z. & Pneumonia/influenza NOS & \\
\hline
\end{tabular}


SUPPLEMENT FIGURE 1: The most commonly prescribed antibiotics for all-cause pneumonia treatment in children $<10$ year-olds

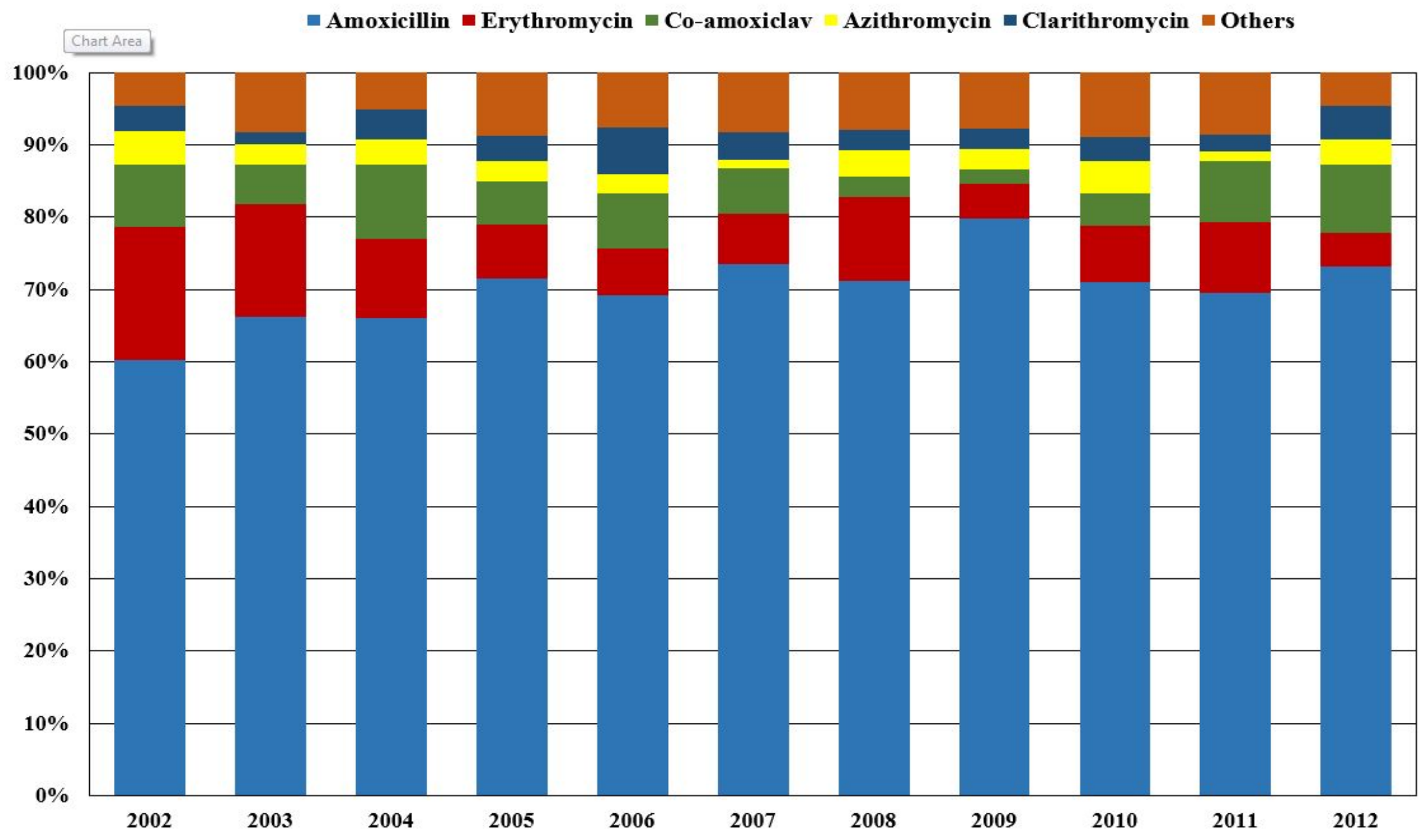

